\title{
Current Evidence on Reliability of Guided Implant Surgery
}

\author{
Sunil K Mishra ${ }^{1}$, Ramesh Chowdhary ${ }^{2}$ \\ International Journal of Prosthodontics and Restorative Dentistry (2020): 10.5005/jp-journals-10019-1296
}

Since past few years, the digital technologies which include computed tomography (CT), cone-beam computed tomography (CBCT), and computer-aided design/computer-aided manufacturing (CAD/CAM), have simplified the treatment planning and surgical procedures for implant-supported rehabilitation. ${ }^{1}$ Developments in CBCT and intraoral scanning have facilitated the transition from traditional manual dental impressions and treatment planning to a complete digital implant workflow. ${ }^{2}$ The digital work flow helps in virtual designing of the implant position, fabrication of the interim prosthesis in case of patients with immediately loaded implants with ease in communication with the clinic, patient and laboratory. ${ }^{1}$

The guided surgery software helps in the prosthetically driven virtual planning of the ideal implant positions, which allows three-dimensional visualization prior to implant surgery. A stereolithographic surgical template helps in transferring the virtual planned implant position to the real clinical situation. ${ }^{3}$

Whether guided surgery has an edge over conventional implant placement is not very clear. Walker-Finch and Ucer in their systematic review with five-year survival rates for implants placed using digitally designed static surgical guides concluded that, dental implants placed using a digitally designed static surgical drill guide have cumulative survival rates which was comparable with the implants placed using the conventional technique. ${ }^{2}$ Yogui et al. in their systematic review and mea analysis compared computerguided implant placement with free hand implant placement. They found that both computer-guided and freehand surgeries yielded similar results for mechanical, biological complications, marginal bone loss, and implant survival rate. ${ }^{1}$

Zhou et al. in their systematic review studied the clinical accuracy of guided implant surgery and analyzed the clinical factors affecting it. They concluded that the position of guide, whether in maxilla or mandible, fixation of guide with screw or not, totally or partially guided, using open flap or flapless technique influences the accuracy of the computer aided implant surgery. According to them, totally guided systems with fixed screws followed by flapless approach had greater accuracy. ${ }^{4}$ Colombo et al. compared the computer guided implant placement with conventional treatment protocols in their review on randomized controlled trial studies. They found a low evidence on image guided implant placement. There were no statistically significant differences between computer-guided and conventional implant placement procedures based on patient outcomes and implant survival rate. ${ }^{5}$
${ }^{1}$ Department of Prosthodontics, Rama Dental College Hospital and Research Centre, Kanpur, Uttar Pradesh, India

${ }^{2}$ Department of Prosthodontics, RajaRajeswari Dental College and Hospital, Bengaluru, Karnataka, India

Corresponding Author: Sunil K Mishra, Department of Prosthodontics, Rama Dental College Hospital and Research Centre, Kanpur, Uttar Pradesh, India, Phone: +91 7697738478, e-mail: sunilmsr200@yahoo. co.in

How to cite this article: Mishra SK, Chowdhary R. Current Evidence on Reliability of Guided Implant Surgery. Int J Prosthodont Restor Dent 2020;10(4):137.

Source of support: Nil

Conflict of interest: None

Although current literature is very limited on guided implant surgery and the evidence present has not provided any convincing results which can be detrimental to implant survival rates. However, still indications for guided implant surgery could be the need for minimally traumatic or flapless surgery, optimal implant positioning and immediate loading. More RCT's are needed to be performed in order to provide clear evidence so that guided surgery can be adopted successfully in clinical practice.

\section{References}

1. Yogui FC, Verri FR, de Luna Gomes JM, et al. Comparison between computer-guided and freehand dental implant placement surgery: a systematic review and meta-analysis. Int J Oral Maxillofac Surg 2021;50(2):242-250. DOI: 10.1016/j.ijom.2020.08.004.

2. Walker-Finch $\mathrm{K}$, Ucer C. Five-year survival rates for implants placed using digitally-designed static surgical guides: a systematic review. Br J Oral Maxillofac Surg 2020;58(3):268-276. DOI: 10.1016/j. bjoms.2019.12.007.

3. Spielau T, Hauschild U, Katsoulis J. Computer-assisted, templateguided immediate implant placement and loading in the mandible: a case report. BMC Oral Health 2019;19:55. DOI: 10.1186/s12903-0190746-0.

4. Zhou W, Liu Z, Song L, et al. Clinical factors affecting the accuracy of guided implant surgery-a systematic review and meta-analysis. J Evid Based Dent Pract 2018;18(1):28-40. DOI: 10.1016/j.jebdp.2017.07.007.

5. Colombo M, Mangano C, Mijiritsky E, et al. Clinical applications, and effectiveness of guided implant surgery: a critical review based on randomized controlled trials. BMC Oral Health 2017;17:150. DOI: 10.1186/s12903-017-0441-y.

(c) Jaypee Brothers Medical Publishers. 2020 Open Access This article is distributed under the terms of the Creative Commons Attribution 4.0 International License (https://creativecommons.org/licenses/by-nc/4.0/), which permits unrestricted use, distribution, and non-commercial reproduction in anymedium, provided you give appropriate credit to the original author(s) and the source, provide a link to the Creative Commons license, and indicate if changes were made. The Creative Commons Public Domain Dedication waiver (http://creativecommons.org/publicdomain/zero/1.0/) applies to the data made available in this article, unless otherwise stated. 